\title{
Examining the influence of pre-service teachers' digital native traits on their technology acceptance: A Serbian perspective
}

\author{
Verica Milutinović ${ }^{1}$ (D)
}

Received: 17 October 2021 / Accepted: 3 January 2022 / Published online: 12 January 2022

(c) The Author(s), under exclusive licence to Springer Science+Business Media, LLC, part of Springer Nature 2022

\begin{abstract}
Many seem to believe that today's pre-service teachers as born after 1980 are digital natives, or that they are "native speakers" of the digital language. Nevertheless, there is no evidence that their digital native characteristics determine whether or not they would use technology in the classroom. Although not widely evaluated, the four-factor, 21-item Digital Nativity Assessment Scale (DNAS) was one of the first instruments to assess digital nativeness (DN). This study aim is to explore the influence of pre-service teachers' $\mathrm{DN}$ on their intention to use technology in the future classroom in Serbia, by evaluating the DNAS on Serbian sample and using it for measuring the DN. Six variables were incorporated to examine their mutual relationships based on technology acceptance model: digital nativeness, behavioral intention (BI), perceived usefulness (PU), perceived ease of use (PEU), subjective norm (SN), and technological complexity (TC). Data were collected from 688 preservice teachers in Serbia. Exploratory factor analysis confirmed a four-factor model for the DNAS, and Serbian pre-service teachers demonstrated a high level of DN. To evaluate the hypothesized model structural equation modeling was utilized. The suggested model had a good fit for describing the BI of Serbian pre-service teachers, accounting for $27.1 \%$ of the variance in BI. It was found that direct dominant predictors of BI are digital native traits, perceived usefulness, and perceived ease of use. Significant influence of digital native traits on all other variables in the model was also confirmed. The implications for theory and practice are discussed.
\end{abstract}

Keywords Digital natives · Pre-service teachers $\cdot$ Scale validation $\cdot$ Technology acceptance $\cdot$ Serbia

Verica Milutinović

verica.milutinovic@pefja.kg.ac.rs

1 Faculty of Education, University of Kragujevac, Jagodina, Serbia 


\section{Introduction}

Almost every aspect of civilization is influenced by technology. Todays' education has the explicit goal of assisting students in becoming digitally literate citizens capable of coping with the dynamics and complexities of today's society (Fraillon et al., 2014). Technology integration in education has gotten a lot of attention and discussion among educational stakeholders, due to COVID-19 sweeping the globe. Because of that, teachers and teacher educators are urged to use technology into their classrooms, either as a learning aid (i.e. through various synchronous online teaching platforms) or a formative evaluation method (Straub, 2009; Zhao \& Zhao, 2021). However, this advancement demands the effective integration of technology into learning and teaching environments (OECD, 2015; Siddiq et al., 2016). For this purpose, it is important to understand the behavioral characteristics of students and especially their teachers as any attempt to integrate technology into the learning and teaching process relies heavily on the support of teachers engaged (Prensky, 2007).

Prensky (2001) introduced the phrase "digital natives" referring to people born after 1980 who are conversant with digital technology, and utilize them for a variety of purposes as they grew up in the digital era. "Digital immigrants" has been coined to characterize their older counterparts, who rather than growing up with digital systems, learn about them later in life (Prensky, 2001).

According to Prensky (2001) digital natives: are accustomed to getting information in a very short period of time; enjoy parallel processing and multitasking; prefer visuals to text rather than the other way around; operate best when they are connected; prefer access that is random (like hypertext); thrive on frequent rewards and instant gratification; would rather play games than do "serious" work. Digital nativeness is defined in this study as the degree to which a person embodies the traits associated with digital natives.

Nevertheless, some academics dismiss the concept of the digital native, even calling it a myth (Bennett \& Maton, 2010; Kirschner \& De Bruyckere, 2017). However, Judd's (2018) findings show that the term is still being utilised in studies. Despite harsh criticism, the digital native frame has had such an influence on academics and practitioners that it continues to inform research practice in education (Kesharwani, 2020; Kirschner \& De Bruyckere, 2017; Helsper, 2020; Huang et al., 2021). Wilson et al. (2020) suggest that a greater understanding of this suggested phenomena or the continuous development of a better model for comprehending the needs of generations beyond 1980 are both required.

The researchers argue about whether age or other variables should be used to define digital natives (Huang et al., 2021). Socially advantaged older people have been found to be more tech-savvy than socially disadvantaged younger ones (Hsieh et al., 2011). Thinyane (2010) found that not only are students in a single developing country diverse in terms of technology usage and experience, but that there are also differences in students' experiences among 
developing and developed countries. Helsper (2020) analysed internationally comparative datasets and found that young people continue to face challenges in participating in digital societies. Differences exist in access, digital media use, skills, as well as the positive and negative effects that result. Inequalities will remain until the socio-digital environment improves (Helsper, 2020). On the other hand, Huang et al. (2021) found that experienced university teachers in China also demonstrate clear digital native traits that are similar to those of digital native students.

Helsper and Eynon (2010) noted that a multigenerational perspective has been exaggerated, and that all individuals living in the digital age should have comparable characteristics, regardless of generation. It is more important to determine if a person's digital orientation is determined by their date of birth or by their level of experience, exposure, or competence with new technologies (Helsper \& Eynon, 2010).

This study aims to distinguish digital users based on their behavioral characteristics rather than their age. For that purpose, we used Digital Natives Assessment Scale (DNAS), a 21-item, 4-factor model (Teo, 2013), to measure digital nativeness. Despite the fact that it has not been widely validated, the scale could be useful in evaluating participants' attitudes and behaviors in relation to the common traits associated with digital natives.

Researchers are struggling to understand what are the obstacles and motivators for teachers' use of technology in schools. By concentrating on teachers' acceptance of technology, a large body of literature has been published about the factors that influence this inclusion (Straub, 2009). The Technology Acceptance Model (TAM) has dominated the research scene. Individual behavioural intention to use technology is studied as a dependent variable in most studies on technology acceptance in education, as it have been proven to impact actual use (Mei et al., 2018; Teo, 2009b; Teo \& Milutinović, 2015; Teo et al., 2017).

Many variables can influence teachers' intentions to use technology for future teaching. Scherer et al. (2019) summarized the current body of research on pre-service and in-service teachers' technology acceptance based on TAM by analyzing 114 empirical studies using a combination of meta-analysis and structural equation modeling techniques. They found that TAM explains technology acceptance well, yet, the importance of external variables has been stressed out.

Because of their current status as students, and possibly digital natives, as well as their future profession as teachers, pre-service teachers from a developing country were chosen for this study. Pre-service teachers, who are digital natives according to Prensky's (2001) description, should be eager to employ technology in the classroom just because they have grown up with it. However, there is no evidence that their DN traits actually predict their intention to use technology in the classroom. From the literature, no research concerning the influence of digital native traits on pre-service teachers' adoption of technology has been located. This research will focus on examining the DNAS scale on Serbian sample for measuring digital native traits in order to investigate the influence of these characteristics on pre-service teachers' intention to utilise technology in future teaching using the extended TAM. 


\section{Literature review}

\subsection{Research in technology acceptance}

Several intention-based acceptance/adoption theories have been developed throughout the years to explain and predict technology uptake. The majority of them have been empirically tested in a variety of educational settings. Some of the most popular and studied models and theories are Fishbein and Ajzens' theory of reasoned action (TRA) (Fishbein \& Ajzen, 1975), technology acceptance model (TAM) (Davis et al., 1989), Ajzens' (Ajzen, 1991) theory of planned behavior (TPB), and the unified theory of acceptance and use of technology (UTAUT) (Venkatesh et al., 2003). In these, technology acceptance was defined or assessed as a behavioral intention, and/or use (self-reported or observed) (Davis, 1989; Davis et al., 1989; Pynoo et al., 2012; Venkatesh et al., 2003). Teo and van Schaik (2012) evaluated four models (TAM, TPB, TRA, and integrated) to see which one predicted pre-service teachers' intentions to utilize technology the best. The results, however, show that the models' explanatory power is similar.

Due to its ability to explain variance in the intention to use technology or actual usage, as well as the ease with which it can be specified within structural equation modeling frameworks, the TAM has gained popularity and is arguably the most powerful framework for describing users' acceptance of technology in education (Scherer et al., 2019). The TAM mainly comprises perceived ease of use (PEU), and perceived usefulness (PU) in explaining behavioral intentions (BI) directly or indirectly (Davis, 1989). PEU is defined as "the degree to which a person believes that using a particular system would be free of effort" while PU refers to "the degree to which a person believes that using a particular system would enhance his or her performance" (Davis, 1989, p. 320). The degree of willingness to use technology reflects one's behavioral intention. Furthermore, according to the TAM, users' perceptions of a technology's usefulness and ease of use affect their attitudes toward it, which influence their behavioral intentions to use it. On the other hand, Venkatesh et al. (2003) argue that when constructs linked to performance and effort expectations are included in the model, the attitudinal components become insignificant. Thompson et al. (1991) found that attitude had no relevance in the presence of such other constructs. Additionally, Teo (2009a) found that attitude had no effect on the overall variance accounted in technology usage by a sample of pre-service teachers showing the TAM's attitude construct to be unnecessary. Hence, attitude toward use of technology was omitted from this study.

The TAM defines the relationships between users' PU, PEU, and their BI (Davis et al., 1989; Pynoo et al., 2012; Venkatesh et al., 2003). The direct and indirect influences of PEU and PU are proposed to affect intention to use technology. Furthermore, the PEU is hypothesized to have a direct significant influence on PU.

Based on the previous, the following hypotheses were formulated: 
H1: perceived usefulness (PU) significantly influences behavioral intention (BI).

H2: perceived ease of use (PEU) significantly influences behavioral intention ( BI).

H3: perceived ease of use (PEU) significantly influences perceived usefulness (PU).

TAM has been widely praised; however, its parsimonious nature, robustness, and predictive ability have been criticized for being restricted to a specific context and for offering only basic information about the adoption of a certain technology (Tsai, 2015). Since the original TAM was designed and verified as a model to be utilized in western developed countries, critics also focused on its limited application in education settings in developing countries (Teo et al., 2018). Furthermore, in developing countries, there has been little study on pre-service teachers' intentions to use ICT in their teaching practice (Teo \& Milutinović, 2015; Teo et al., 2017).

There have been suggestions that the model should be extended and expanded with external variables to address more sophisticated educational relationships in order to improve its explanatory power (Abdullah \& Ward, 2016). Multiple extended TAM models have been proposed and validated for understanding the intention of pre-service and in-service teachers to utilize different technologies (e.g., Fathali \& Okada, 2018; Mei et al., 2018; Munoz-Carril et al., 2020; Teo et al., 2017; Teo \& Van Schalk, 2009). Different external variables from other theories, such as TRA, TPB, and UTAUT, have been adopted in these extended TAMs. There is a body of research with extended TAMs in investigating the acceptance of technology among pre-service teachers (Liu et al., 2019; Mei et al., 2018; Teo \& Milutinović, 2015; Teo et al., 2017; Teo et al., 2019a, 2019b). In order to investigate pre-service teachers' intention to use technology among Serbian participants an extended TAM was used in this study.

\subsection{Subjective norm}

Subjective norm is defined in TRA (Fishbein \& Ajzen, 1975) as “the person's perception that most people who are important to him or her think he or she should or he or she should not perform the behavior in question" (p. 302). The degree to which pre-service teachers in Serbia regard the expectations of the "essential" or "referent" people (e.g. leaders, teachers, students, colleagues) in our study is referred to as the subjective norm. As digital natives function best when networked with other people, we expect that subjective norm will be an important factor in determining pre-service teachers' intentions to use technology.

One of the key variables in the TRA, TPB, and UTAUT theories, with direct or indirect influence on BI is subjective norm or social influence. The original TAM was extended in many educational contexts by incorporating subjective norm as an external variable (Ma et al., 2005; Teo \& Milutinović, 2015). Multiple meta-analyses using teacher samples found that SN had a positive influence on both PEU and PU (Abdullah \& Ward, 2016; Schepers \& Wetzels, 2007; Scherer et al., 2019). 
In the combined meta-analysis with structural equation modeling of 114 empirical studies, Scherer et al. (2019) found subjective norm to be one of the most important predictors of PU, and important in predicting PEU. Abdullah and Ward (2016) in the meta-analysis of 107 scholar papers found positive influence of SN on both PEU and PU, with larger effects on PEU, which was also confirmed in meta-analysis of Scherer et al. (2019). Mei et al. (2018) found a significant influence of SN on PU in a research exploring the factors that influence pre-service EFL teachers' intention to utilize Web 2.0 technology for language instruction in the People's Republic of China. Similar results were confirmed by Teo and Milutinović (2015) in the study on pre-service teachers' intention to utilise technology in the mathematics classroom in Serbia. In the research on technological adoption, the impact of SN on behavioral intentions has been well documented (Taylor \& Todd, 1995; Teo et al., 2019a). Previous research on university students' intentions to use Internet-based technologies, have also confirmed the influence of subjective norm on PU, PEU and BI (Huang et al., 2020b).

Based on the above, we formulated the following hypotheses:

H4: SN significantly influences PU.

H5: SN significantly influences BI.

H6: SN significantly influences PEU.

\subsection{Technological complexity}

Thompson et al. (1991) used Rogers and Shoemakers' (Rogers \& Shoemaker, 1971) definition of complexity as "the degree to which an innovation is perceived as relatively difficult to understand and use" (p. 154) to define complexity of PC use. In our study, students' perceptions of the difficulties with understanding and using technology are referred to as technological complexity (TC). Although TC and PEU may share some similarities, these two constructs are considered different because the PEU measures the effort needed to use technology, whereas TC refers for the amount of time and difficulty it takes to understand and use technology (Teo et al., 2018).

In order to examine technology acceptance among pre-service teachers, Teo (2009b) surveyed 475 participants in Singapore and found that TC has a significant influence on PEU. In another study, Teo et al. (2018) investigated English teachers' intentions to use technology in their classroom practice in China and found that PEU was significantly negatively influenced by TC. This relationship was also confirmed in subsequent studies on university students' acceptance of different online technologies (Khlaisang et al., 2021; Teo et al., 2019b).

Although pre-service teachers are in the age group that represent digital natives who are supposed to be familiar and grew up with technology (Huang et al., 2021; Prensky, 2001; Teo, 2016), they may still meet certain challenges when using it for learning. Additionally, since they are used to receiving information really fast and thrive on instant rewards and gratification, it is reasonable to expect that additional 
time demanded for learning how to use some technology might negatively influence their perception of ease of use.

Therefore, we proposed the following hypothesis.

H7: TC significantly negatively influences PEU.

\subsection{Digital natives}

Prensky (2001) used the phrase "digital natives" in educational settings to describe a young generation of pupils who utilise a variety of technologies and are fluent in the digital languages of computers, digital games, videos, and social media on the Internet.

New generations are constantly connected to the rest of the world through a variety of technologies that have become ingrained in their daily lives (Prensky, 2001; Bennett et al., 2008). According to previous studies, younger people place a greater importance on the PU of new technology and perceive it easier to use than older generations (Chung et al., 2010). Because they are more familiar with and oriented to omnipresent technology, younger generations are more likely to perceive them as effortless than older generations (Chung et al., 2010). Morris et al. (2005) found that individual differences among users are essential in understanding how and why users choose various technological choices. However, although pre-service teachers in this age group are familiar with Internet use and grew up with technologies (Huang et al., 2021) not all of them are digital natives. Participants who used technology for longer periods of time scored higher on the DNAS, suggesting that the participants' computer experience influenced their perception of their digital native status (Teo, 2016). While most pre-service teachers considered themselves to be digital natives, Teo et al. (2016) found that significant differences were identified primarily in perceived competence and years of computer usage, with no significant differences observed for age or gender.

Metallo and Agrifoglio (2015) found that digital natives are under more social pressure to use Twitter, and they believe it to be easier to use, although less useful, than digital immigrants. Perceived usefulness, instructors' influence, compatibility, and behavioral intention were shown by Kesharwani (2020) to be more important factors in DNs' acceptance of an IS than that of digital immigrants under sequential belief updating.

Zhao and Zhao (2021) emphasized the importance of including variables such as digital native traits when studying users' technology adoption. They found that digital native traits were significantly related to PU, PEU, computer self-efficacy, attitudes, and BI, indicating their ability to predict university faculties' adoption of online teaching.

Pre-service teachers with a greater level of digital nativeness are more likely to see technology as an easy to use beneficial tool in their future teaching. Also, the social pressure on digital natives to use technology is greater (Metallo \& Agrifoglio, 2015), and they will be more open to use it in their future classroom.

Therefore, we formulated the following hypotheses: 
H8: digital nativeness (DN) significantly influences perceived usefulness (PU). H9: digital nativeness (DN) significantly influences subjective norm (SN).

H10: digital nativeness (DN) significantly negatively influences technological complexity (TC).

H11: digital nativeness (DN) significantly influences perceived ease of use (PEU).

H12: digital nativeness (DN) significantly influences behavioral intention (BI).

\subsection{DNAS in measuring pre-service teachers' digital native traits}

Teo (2013) proposed Digital Natives Assessment Scale (DNAS), a self-report instrument, which has been designed to measure digital native traits. Teo (2013) recognized four characteristics that distinguish students' digital native (DN) traits as they: have grown up with technology (Tech), rely on graphics to communicate (Graph), are comfortable with multitasking (Multi), and thrive on immediate gratification and rewards (Reward).

Multiple researches have used the DNAS to assess students from various cultures and to investigate correlations between digital native traits and other technology-centric variables since its release (Akçayır et al., 2016; Shonfeld et al., 2021; Wang et al., 2019; Yurdakul, 2018). Few research, on the other hand, has sought to validate the structure in diverse populations (Chen et al., 2016; Huang et al., 2021; Teo, 2016; Teo et al., 2016; Wagner \& Acier, 2017; Wilson et al., 2020). According to previous validation studies, the DNAS instrument verified by Teo (2013) and the accompanying model structure fit the data in French, Turkish, Taiwanese, and Chinese populations. Although it was not found to be entirely applicable in the United States population (Wilson et al., 2020) it contributes to the debate about digital nativeness. For example, Huang et al. (2021) assessed DNAS' factor structure among Chinese university professors and examined their "digital native" characteristics. Their findings back up the DNAS' measurement invariance across age, technology use years, teaching experience, and technology-assisted teaching years.

\subsection{Present study}

This study aims to examine the four-factor structure of the DNAS, the level of pre-service teachers' digital native traits and whether DN in connection with the above discussed variables might significantly predict pre-service teachers' intentions to utilize technology for teaching in Serbian primary schools. This study's utilization of pre-service teachers is designed to help us better understand how future teachers, as probably digital natives, could respond to technology.

Serbia is a developing country in south-eastern Europe with a population of 7.12 million people. Serbian primary education is free and compulsory, and it is divided into two cycles of four years each: grades one to four and grades five to eight. Secondary education is available for free, although it is not compulsory. 
Teachers at primary schools (grades one to four) receive their education at faculties of education, whereas those in upper primary (grades five to eight) and secondary schools obtain their education at faculties that specialize in related fields (faculties of language, science, arts, and so on) (UNESCO-IBE, 2011).

Only a few studies have looked at the variables that impact Serbian pre-service teachers' intentions to utilize technology to date, mainly in the mathematics classroom (Milutinović, 2016; Teo \& Milutinović, 2015; Teo et al., 2017). Researchers in Serbia, as well as those in other developing countries, are interested in knowing more about the important factors in implementing technology in the classroom (Mei et al., 2018; Teo et al., 2014; Kafyulilo et al., 2015).

Using the above-mentioned acceptance theories and models, a research model was constructed for this study (see Fig. 1), which encapsulates six main factors: PEU - perceived ease of use, PU - perceived usefulness, TC - technological complexity, SN - subjective norm, BI - behavioural intention to use technology, and DN - digital nativeness.

In accordance with the hypotheses, this study tries to answer the following research questions:

- Is the DNAS four-factor structure, which was previously identified, also present among pre-service teachers in Serbia, and what is the level of their digital native traits?

- How well does the research model (TAM plus digital nativeness, technological complexity, and subjective norm) describe intentions of pre-service teachers to utilize technology in Serbian primary schools?

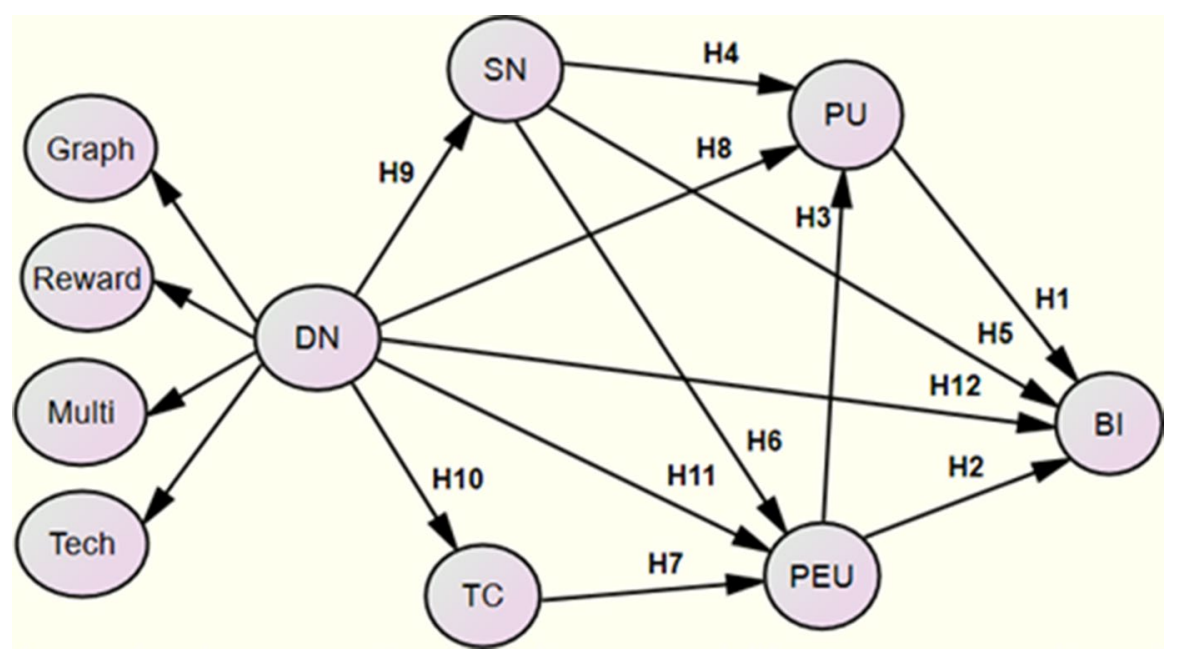

Fig. 1 Research model. Note: PEU = perceived ease of use, PU=perceived usefulness, TC=technological complexity, $\mathrm{SN}=$ subjective norm, $\mathrm{BI}=$ behavioural intention to use technology, Graph=reliant on graphics for communication, Reward = thrive on instant gratifications and rewards, Multi=comfortable with multitasking, Tech = grow up with technology, and DN= digital nativeness 


\section{Method}

\subsection{Research participants and procedure}

There were 688 pre-service teachers from faculties for teacher education in Serbia that participated in this study. In addition, each student who took part in the study was given informed permission, stating that their participation was optional, that any data gathered was de-identified, and that the information supplied was only for educational reasons. Justice, respect, autonomy, kindness, and secrecy were all protected as ethical values. The Research ethics Committee of the university affiliated with this study authorized all of the research techniques utilized in this investigation.

With their consent, pre-service teachers voluntarily participated in this research. The mean age of the participants was 20.92 years (Standard deviation $(\mathrm{SD})=2.76$ ), and $9.6 \%$ (66) were males. The items in the survey were all provided in Serbian and were completed in the Google form questionnaires. Participants were informed about the study's aim as well as their right to withdraw from the questionnaire at any time before or during completing it. The survey took about $15 \mathrm{~min}$ to complete.

\subsection{Instrument}

In this study, the two-part multi-item research instrument is designed to explore participants' intentions to use technology. The first part of the survey was intended for collecting participants' demographic information, such as gender and age. The second part was designed for collecting participants' self-reports on six variables and consisted of subscales for DN - digital nativeness (21 items - DNAS), PEU - perceived ease of use (4 items), PU - perceived usefulness (4 items), TC - technological complexity (3 items), SN - subjective norm (3 items), and BI - behavioural intention to use technology ( 3 items). Five-point Likert scale (from $1=$ strongly disagree, to $5=$ strongly agree) was used to measure each item, except for DN where seven-point Likert scale was used (from $1=$ strongly disagree, to $7=$ strongly agree). Listed in the Appendix are all the items utilized in this examination, which were drawn from multiple published sources with well-documented reliabilities.

The author translated the DNAS and other scales, which were then evaluated by professor of English as a foreign language at the same university. Iterations were addressed as long as both translators were not in agreement. An external bilingual individual then edited a common version, which was subsequently back translated into English.

Thinyane (2010) found that use and access to different technologies is very diverse in developed and developing countries. However, mobile phone is a tool that South African students have a lot of access to and usage of (Thinyane, 2010). Yong and Gates (2014) also found that majority of students have full access to mobile computer, smart phone, and broadband Internet. To avoid these potential differences. we used the term technologies (i.e. personal computer, laptop, smartphone, tablet and Internet) instead of computer in all research scales. 


\subsection{Data analysis}

An exploratory factor analysis (EFA) was utilized to investigate the underlying structure of the DNAS. We employed structural equation modeling (SEM) to analyse the data, which involves first testing for normality of the data and then building the research model. SEM is useful for analysing observed and latent variables relationships (Hoyle, 2011), and it is consistent with how hypotheses are conceptualized and stated statistically. Statistical operations were carried out with SPSS 17.0 and Amos 18.0, and the maximum likelihood approach was utilized to estimate parameters.

Following recommendations of Anderson and Gerbing (1988), in a two-step approach, we started by estimating the measurement model, followed by estimating the structural model. The measurement model depicts how effectively unobserved (i.e. latent) constructs are measured by the observed indicators (i.e. items in the survey). Using the six constructs for this study, the measurement model was described as a congeneric model with uncorrelated errors. The hypothesized relationships in the model between the endogenous and exogenous variables were investigated in the next step.

Researchers propose a minimum sample size of 200 (Boomsma, 1987) when employing maximum likelihood estimation in SEM to obtain reliable findings. For data analysis in this study maximum likelihood was considered to be an appropriate approach because the sample size was 688 .

Researchers have also advocated Hoelter's critical N, which specifies how small a sample size must be for a result to be no longer significant (alpha=0.05). Given the sample size of 688, and Hoelter's critical $\mathrm{N}$ of 335, SEM is considered an acceptable approach for the analysis of the data.

Table 1 Descriptive statistics of the study constructs

\begin{tabular}{lllll}
\hline Construct & Mean & $\begin{array}{l}\text { Standard } \\
\text { deviation }\end{array}$ & Skewness & Kurtosis \\
\hline Age & 20.92 & 2.76 & 4.80 & 32.85 \\
Perceived usefulness (PU) & 4.21 & 0.80 & -1.03 & 1.05 \\
Perceived ease of use (PEU) & 4.11 & 0.76 & -0.78 & 0.49 \\
Subjective norm (SN) & 3.43 & 1.00 & -0.31 & -0.31 \\
Technological complexity (TC) & 1.94 & 0.88 & 0.83 & -0.14 \\
Behavioural intention to use technology (BI) & 3.96 & 0.90 & -0.82 & 0.59 \\
Digital nativeness (DN) & 5.53 & 0.90 & -0.77 & 0.93 \\
Grow up with technology (Tech) & 5.89 & 1.11 & -1.35 & 1.71 \\
Comfortable with multitasking (Multi) & 5.68 & 1.22 & -1.08 & 0.73 \\
Reliant on graphics for communication (Graph) & 4.58 & 1.46 & -0.34 & -0.67 \\
Thrive on instant gratifications and rewards (Reward) & 5.97 & 1.00 & -1.33 & 1.88 \\
\hline
\end{tabular}




\section{Results}

\subsection{Descriptive statistics}

The descriptive statistics of the variables as calculated by SPSS, are shown in Table 1. With the exception of TC, the means of all constructs were above the scale's midpoint of 3.00 (4.0 for DN), which indicated mostly favorable responses to the constructs of the model. Except for the Age, the skewness and kurtosis were found to be within the level guidelines, i.e. |3| and I10| (Schumacker \& Lomax, 2010; Kline, 2011). Therefore for this study's data, univariate normality was assumed.

\subsection{DNAS analysis and pre-service teachers' level of DN}

To investigate the underlying structure of the DNAS, an exploratory factor analysis utilizing principle components analysis (PCA) with varimax rotation was performed on the 21 items, similar to Teo (2013). The number of components was determined

Table 2 Exploratory factor analysis of the DNAS

\begin{tabular}{lllll}
\hline & Component & & \\
\cline { 2 - 5 } & 1 & 2 & 3 & 0.711 \\
\hline DN1 & & & 0.773 \\
DN2 & & & 0.571 \\
DN3 & & & 0.701 \\
DN4 & & & 0.648 \\
DN5 & & & \\
DN6 & 0.630 & & \\
DN7 & 0.647 & & & \\
DN8 & 0.720 & & & \\
DN9 & 0.818 & & & \\
DN10 & 0.672 & & & \\
DN11 & 0.658 & & & \\
DN12 & & 0.712 & & \\
DN13 & & 0.782 & & \\
DN14 & & 0.865 & & \\
DN15 & & 0.823 & & \\
DN16 & & 0.602 & & \\
DN17 & & & 0.571 & \\
DN18 & & & 0.734 & \\
DN19 & & & & \\
DN20 & & & & \\
DN21 & & & & \\
\hline
\end{tabular}

Extraction Method: Principal Component Analysis; Rotation Method: Varimax with Kaiser Normalization 
using Kaiser's eigenvalues-larger-than-one criteria, which retains all factors with eigenvalues larger than 1.0. Additionally, Hair Jr. et al. (2010) have recommended a factor loading of \pm 0.50 for items to achieve the minimum level of practical significance for interpretation. As shown in Table 2, the four-factor structure was confirmed with acceptable loadings of all items.

Based on this, according to Teo's (2013) factor pattern, items were divided into four constructs and our research model was tested using a second order model for the DN.

As shown in Table 1, the DNAS constructs' mean scores for pre-service teachers varied from 4.58-5.97 (SD ranged from 1.00 to 1.46). Furthermore, cumulative percent of means below the scale's midpoint of 4.0 for DN was $5.7 \%$, for Tech $6.7 \%$, Multi $10.2 \%$, Graph $32.4 \%$, and for Reward $4.7 \%$. This answered the first research question.

\subsection{Evaluation of the measurement model}

The measurement model with uncorrelated errors was evaluated using confirmatory factor analysis (CFA) and maximum likelihood estimation (MLE). We looked at Mardia's (1970) normalized multivariate kurtosis value, since the MLE technique presume multivariate normality of the perceived variables. For the present sample data, the Mardia's coefficient was 414.61, which was lower than 1520, as computed using the formula $\mathrm{p}(\mathrm{p}+2)$, where $\mathrm{p}(38)$ is the model's number of observed items (Raykov \& Marcoulides, 2008). We assumed multivariate normality of the data based on this.

We used the composite reliability (CR) and average variance extracted (AVE) to determine the data's reliability, both of which are considered sufficient when they surpass or equal 0.50 (Fornell \& Larcker, 1981). In addition, the items' standardized estimates were examined. If an item's standardized estimate is larger than 0.50 , it adequately explains the underlying construct (Hair Jr. et al., 2010). The constructions' standardized estimates, AVEs, and CRs, were all within acceptable limits (Table 3) except for Tech and Multi with AVEs less than 0.5. Nevertheless, since CRs for Tech and Multi were higher than 0.6, the convergent validity of the constructs was still adequate (Fornell \& Larcker, 1981).

We used the ratio of the $\chi^{2}$ to its degree of freedom $(\chi 2 / \mathrm{df})$ and the minimum fit function $\left(\chi^{2}\right)$, to assess the measurement model's fit, with a value of 3.0 being regarded optimal (Kline, 2011). The Comparative Fit Index (CFI) and Tucker-Lewis Index (TLI) were also included, where acceptable fit is indicated by values greater than 0.90 (Hair Jr. et al., 2010; Schumacker \& Lomax, 2010).

In addition, the root mean square error of approximation (RMSEA) was consulted, with values less than 0.06 indicating good model fit, as well as the standardised root mean residual (SRMR), with values less than 0.08 showing good model fit (Steiger, 2007). This study's measurement model shows a acceptable fit to the data, according to CFA findings $\left(\chi 2=1400.35, \chi^{2 / \mathrm{df}}=2.25, \mathrm{CFI}=0.94, \mathrm{TLI}=0.93\right.$, RMSEA $=0.043$ [90\% CI: 0.040-0.046], SRMR =0.043). 
Table 3 Estimates of the measurement model

\begin{tabular}{|c|c|c|c|c|c|c|c|}
\hline Variable & Item & SE & UE & t-Value & AVE & $\mathrm{CR}$ & $\alpha$ \\
\hline \multirow[t]{4}{*}{ PU } & PU1 & 0.80 & 0.92 & 26.15 & 0.68 & 0.89 & 0.89 \\
\hline & PU2 & 0.90 & 1.03 & 31.97 & & & \\
\hline & PU3 & 0.88 & 1.00 & & & & \\
\hline & PU4 & 0.69 & 0.77 & 20.97 & & & \\
\hline \multirow[t]{4}{*}{ PEU } & PEU1 & 0.85 & 0.95 & 23.62 & 0.61 & 0.86 & 0.86 \\
\hline & PEU2 & 0.78 & 0.94 & 22.26 & & & \\
\hline & PEU3 & 0.82 & 1.00 & & & & \\
\hline & PEU4 & 0.68 & 0.83 & 17.81 & & & \\
\hline \multirow[t]{3}{*}{ SN } & SN1 & 0.80 & 1.17 & 16.42 & 0.57 & 0.80 & 0.79 \\
\hline & SN2 & 0.78 & 1.08 & 16.27 & & & \\
\hline & SN3 & 0.68 & 1.00 & & & & \\
\hline \multirow[t]{3}{*}{$\mathrm{TC}$} & TC1 & 0.75 & 1.00 & & 0.55 & 0.79 & 0.79 \\
\hline & $\mathrm{TC} 2$ & 0.73 & 1.11 & 16.04 & & & \\
\hline & TC3 & 0.75 & 1.20 & 16.29 & & & \\
\hline \multirow[t]{3}{*}{ BI } & BI1 & 0.85 & 1.00 & & 0.78 & 0.91 & 0.91 \\
\hline & $\mathrm{BI} 2$ & 0.90 & 1.10 & 29.88 & & & \\
\hline & $\mathrm{BI} 3$ & 0.89 & 1.08 & 29.63 & & & \\
\hline \multirow[t]{5}{*}{ Tech } & DN1 Tech & 0.61 & 0.99 & 11.70 & 0.42 & 0.78 & 0.79 \\
\hline & DN2 Tech & 0.67 & 1.30 & 12.42 & & & \\
\hline & DN3 Tech & 0.56 & 1.00 & & & & \\
\hline & DN4 Tech & 0.69 & 1.65 & 12.65 & & & \\
\hline & DN5 Tech & 0.71 & 1.65 & 12.87 & & & \\
\hline \multirow[t]{6}{*}{ Multi } & DN6 Multi & 0.70 & 0.94 & 17.08 & 0.46 & 0.84 & 0.84 \\
\hline & DN7 Multi & 0.75 & 1.00 & & & & \\
\hline & DN8 Multi & 0.60 & 0.71 & 14.60 & & & \\
\hline & DN9 Multi & 0.75 & 0.99 & 18.33 & & & \\
\hline & DN10 Multi & 0.66 & 0.65 & 16.25 & & & \\
\hline & DN11 Multi & 0.62 & 0.88 & 15.16 & & & \\
\hline \multirow[t]{5}{*}{ Graph } & DN12_Graph & 0.65 & 0.85 & 16.57 & 0.57 & 0.86 & 0.85 \\
\hline & DN13_Graph & 0.78 & 1.00 & & & & \\
\hline & DN14_Graph & 0.83 & 1.12 & 21.29 & & & \\
\hline & DN15_Graph & 0.85 & 1.14 & 20.37 & & & \\
\hline & DN16_Graph & 0.62 & 0.75 & 15.85 & & & \\
\hline \multirow[t]{5}{*}{ Reward } & DN17_Reward & 0.57 & 1.07 & 13.62 & 0.50 & 0.83 & 0.82 \\
\hline & DN18_Reward & 0.76 & 1.00 & & & & \\
\hline & DN19_Reward & 0.71 & 1.10 & 18.20 & & & \\
\hline & DN20_Reward & 0.84 & 1.22 & 20.74 & & & \\
\hline & DN21_Reward & 0.64 & 0.92 & 16.32 & & & \\
\hline
\end{tabular}

$\mathrm{PEU}=$ perceived ease of use, $\mathrm{PU}=$ perceived usefulness, $\mathrm{TC}=$ technological complexity, $\mathrm{SN}=$ subjective norm, $\mathrm{BI}=$ behavioural intention to use technology, Tech=grow up with technology, Multi=comfortable with multitasking, Graph=reliant on graphics for communication, Reward=thrive on instant gratifications and rewards, and $\mathrm{DN}=$ digital nativeness; $\mathrm{UE}=$ unstandardized estimates; $\mathrm{SE}=$ standardised estimates; $\mathrm{AVE}=$ average variance extracted; $\mathrm{CR}=$ composite reliability; $\alpha=$ Cronbach's Alpha 


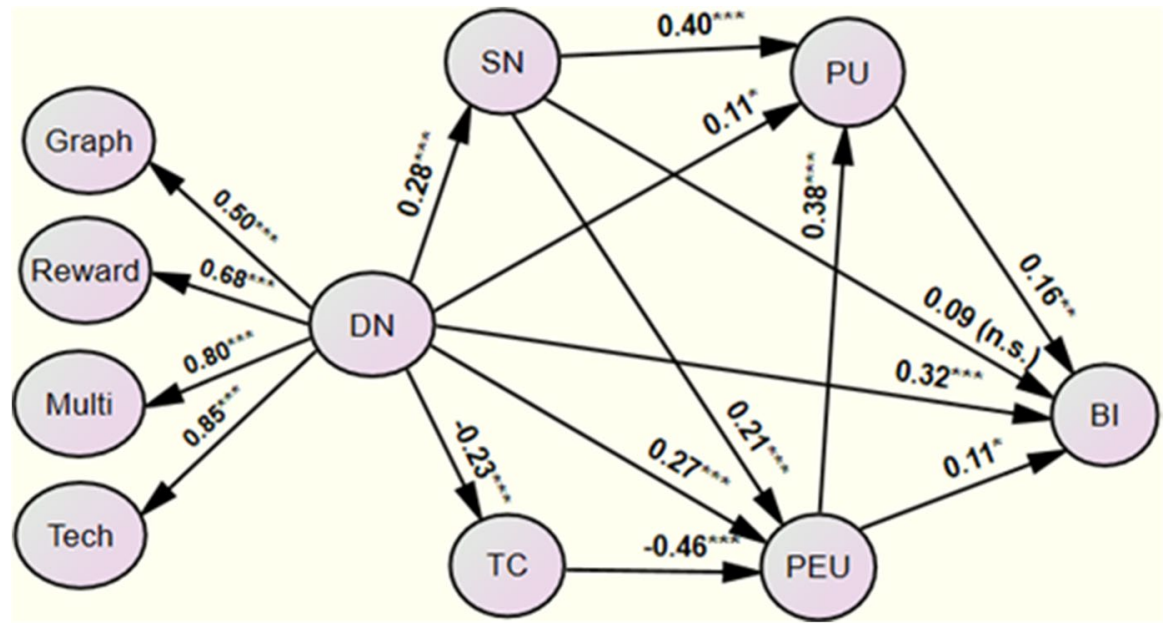

Fig. 2 Results of the hypotheses testing and standardised path coefficients. Note: PEU=perceived ease of use, $\mathrm{PU}=$ perceived usefulness, $\mathrm{TC}=$ technological complexity, $\mathrm{SN}=$ subjective norm, $\mathrm{BI}=$ behavioural intention to use technology, Tech=grow up with technology, Multi=comfortable with multitasking, Graph=reliant on graphics for communication, Reward=thrive on instant gratifications and rewards, and $\mathrm{DN}=$ digital nativeness. The numbers represent the values of standardized direct effects of variables. $* * * \mathrm{p}<0.001, * * \mathrm{p}<0.01, * \mathrm{p}<0.05$

\subsection{Evaluation of the structural model}

After obtaining an acceptable fit for the CFA model (Fig. 2), the structural model's fit was assessed using the same indices and goodness of fit criterias as for the CFA. The structural model in this study had an acceptable fit to the data, according to

Table 4 Testing results of the hypotheses

\begin{tabular}{lllll}
\hline Hypotheses & Path & Path coefficient & t- value & Results \\
\hline H1 & PU $\rightarrow$ BI & 0.160 & $2.890^{* * *}$ & Supported \\
H2 & PEU $\rightarrow$ BI & 0.114 & $2.283^{*}$ & Supported \\
H3 & PEU $\rightarrow$ PU & 0.381 & $9.138^{* * *}$ & Supported \\
H4 & $\mathrm{SN} \rightarrow$ PU & 0.396 & $9.256^{* * *}$ & Supported \\
H5 & $\mathrm{SN} \rightarrow$ BI & 0.086 & 1.725 & Not supported \\
H6 & SN $\rightarrow$ PEU & 0.213 & $5.170^{* * *}$ & Supported \\
H7 & TC $\rightarrow$ PEU & -0.464 & $-10.275^{* * *}$ & Supported \\
H8 & $\mathrm{DN} \rightarrow$ PU & 0.109 & $2.538^{*}$ & Supported \\
H9 & $\mathrm{DN} \rightarrow$ SN & 0.276 & $5.112^{* * *}$ & Supported \\
H10 & $\mathrm{DN} \rightarrow$ TC & -0.228 & $-4.356^{* * *}$ & Supported \\
H11 & $\mathrm{DN} \rightarrow$ PEU & 0.266 & $5.509^{* * *}$ & Supported \\
H12 & $\mathrm{DN} \rightarrow$ BI & 0.316 & $5.756^{* * *}$ & Supported \\
\hline
\end{tabular}

$* \mathrm{p}<0.05 ; * * p<0.01 ; * * * p<0.001$ 
the findings $\left(\chi^{2}=1501.54, \chi^{2 / \mathrm{df}}=2.33, \mathrm{CFI}=0.93, \mathrm{TLI}=0.93, \mathrm{SRMR}=0.052\right.$, RMSEA $=0.044$ [90\% CI: $0.041-0.047])$.

\subsection{Tests of the hypotheses}

The results of testing all 12 hypotheses and three endogenous variables (perceived usefulness, perceived ease of use, and behavioral intention to use technology) are shown in Table 4, and in Fig. 2.

The findings indicated that pre-service teachers' intentions to use technology in their classrooms were significantly influenced by DN, PU, and PEU. On the other hand, PU was significantly influenced by PEU, SN, and DN, while PEU was influenced by TC, DN, and SN.

Out of five endogenous variables in Fig. 2, the direct predictors (TC, DN, and SN) explained $43 \%$ of the variance in the variable PEU. PU's direct predictors (PEU, SN, and DN) explained $46.8 \%$ of its total variance. DN explained $7.6 \%$ of the variance in the SN, and $5.2 \%$ in TC. Finally, the findings indicated that six variables explained $27.1 \%$ of the total variance BI, including direct (DN, PU, and PEU) and indirect influences (TC, PEU, and SN). This provided an answer to the second research question.

\section{Discussion}

This study's goal was to investigate the four-factor structure of the DNAS scale for measuring the level and exploring the influence of digital native traits on pre-service teachers' acceptance of technology in Serbia. We created a study model that included TAM as the core framework, as well as digital nativeness, subjective norm, and technical complexity as external variables. Using structural equation modeling, we found that the suggested research model in this study has an adequate fit to the data collected.

\subsection{Factor structure of the DNAS and the level of pre-service teachers' digital native traits}

The study's initial goal was to assess the DNAS factor structure and investigate the digital nativeness level of Serbian pre-service teachers. Exploratory and confirmatory factor analysis results indicated that data fully fit Teo's (2013) validated 21-item, four-factor model for measuring the perception of digital native traits in Serbian pre-service teachers.

Our findings suggest that the DNAS is a reliable instrument for assessing Serbian pre-service teachers' digital native traits. This finding is consistent with previous studies among in-service teachers in China (Huang et al., 2021) and pre-service teachers in Turkey (Teo et al., 2016), and contrary to the study with American preservice teachers (Wilson et al., 2020). One explanation for these results might be that in all research scales, we used the term technologies instead of computer to 
prevent possible discrepancies. Technologies refer to personal computers, laptops, smartphones, tablets, and the Internet.

Because the majority of the responses on the DNAS items were above the mean level, our findings further suggest that Serbian pre-service teachers demonstrated overall favorable digital native traits. On the other hand, cumulative percent for DNAS constructs' mean scores below the scale's midpoint of 4.0 varied from $4.7 \%$ for Reward to $32.4 \%$ for Graph. This suggests that not all pre-service teachers, although born after 1980, exhibit clear digital native traits, particularly in terms of relying on graphics for communication. Furthermore, the mean values of the four constructions in the DNAS varied from 4.58-5.97 (SD ranged from 1.00 to 1.46), showing that pre-service teachers generally had a positive attitude toward these structures. This is consistent with a recent research (Teo et al., 2016), which found that pre-service teachers responded well to DNAS items (all items were between 3.63 and 6.14, with SD range from 1.25-2.09). This is understandable considering that their mean age was 20.92 years $(S D=2.76)$ meaning that they were born and raised in an era when technology was ubiquitous in terms of accessibility and appeal. On the other hand, our results were more similar to those of Huang et al. (2021) and Zhao and Zhao (2021) who examined the digital native traits of university teachers in China and intentions of Chinese university faculties to employ technology for online teaching respectively. Consistent with Wang et al. (2019), our findings suggest that given the extensive use of technology in educational settings for a variety of purposes, examining individual differences among pre-service, inservice or university teachers by evaluating a number of characteristics of digital natives directly, may provide a more thorough assessment of digital nativeness than the age cohort method.

\subsection{Pre-service teachers' intentions to use technology}

This study examined the extent to which DN, PEU, PU, SN and TC, influenced preservice teachers' behavioral intention (BI) to utilise technology in the future classroom. This was accomplished by determining the significant direct and indirect predictors and assessing the amount of variance in BI explained by PEU, PU, TC, SN and DN.

This study revealed that five factors, DN, PEU, PU, TC, and SN, explained 27.1\% of the variance in BI using structural equation modeling. All of the hypotheses concerning the key TAM variables were supported (H1 to H3), which is consistent with previous research in a variety of educational contexts (Liu et al., 2019; Milutinović, 2016; Pynoo et al., 2012; Teo et al., 2018; Teo \& Milutinović, 2015).

This study indicates that PU was a direct significant positive predictor of BI, implying that pre-service teachers who believe technology is helpful are more inclined to employ it in the classroom. This finding is consistent with research into the factors that impact pre-service teachers' intention to use Web 2.0 tools in the classroom (Teo et al., 2019a). In addition, this study found that PEU has a significant effect on PU, which is consistent with previous TAM research (Mei et al., 2018; Teo et al., 2018; Liu et al., 2019; Teo, 2009b). The data demonstrate that PU mediated 
the impact of PEU on BI. When Serbian pre-service teachers find technology beneficial and easy to use, they are more likely to employ it in their future classrooms.

These findings, which are in line with previous research on pre-service teachers' technology acceptance (Fathali \& Okada, 2018; Munoz-Carril et al., 2020; Teo et al., 2018), backed up the importance of PU and PEU in determining pre-service teachers' intention to use technology.

Pre-service teachers in Serbia appear to need to acquire more favorable opinions about the efficiency and simplicity of use of technology in the classroom in order to be willing to utilize it on a regular basis in their teaching. This may be accomplished through gaining expertise with the use of technology in the classroom.

Contrary to Teo et al. (2019a), and Huang et al. (2020b), no significant effect of SN on BI was identified in this study, rejecting the hypothesis H5. On the other hand, this was in accordance with the findings of other research (Lai \& Chen, 2011; Motaghian et al., 2013; Teo \& Milutinović, 2015), who found no effect of SN on BI. Because of the educational context which is more complex than everyday use of technology, it is possible that this study's participants did not consider the suggestions of significant individuals whose opinions they value as critical to their decisions to employ technology in future teaching. Our results demonstrate that they respect their opinion only through PU and PEU, i.e. if they can demonstrate the usefulness and ease of using technology in the classroom.

Another explanation might be related to the fact that there were much more females in the sample than males comparable to a study with consistent results on the sample of pre-service mathematics teachers in Serbia (Teo \& Milutinović, 2015). Males, on the other hand, dominated the Teo et al. (2019a) pre-service teachers study sample and were relatively equally distributed in the study of Huang et al. (2020b). Cheung et al. (2002) found that male undergraduate students' intentions to utilize an Internet-based learning medium are influenced by subjective norm more than female students' intentions. They argue that collectivist-based sample may be the reason for this result. Collectivism refers to a society in which people are born into strong, cohesive in-groups that continue to protect them for the rest of their lives in exchange for unquestioned devotion (Hofstede et al., 2005). Given the fact that according to Hofstede et al. (2005) Serbia is considered to be a collectivistic society, it is possible that people who are influential in participants' behavior may be their elders. Since they are often less familiar with technologies than younger generations and may not be competent with technology themselves, their recommendations are unlikely to impact young pre-service teachers' technology use in the future classroom.

Furthermore, the findings reveal that PU moderated the effect of SN on BI. The lack of evidence for $\mathrm{H} 5$ and support for $\mathrm{H} 1$ and $\mathrm{H} 4$ demonstrated the mediating impact of SN on BI. The support for $\mathrm{H} 4$ is consistent with some earlier research (Huang et al., 2020b; Teo et al., 2019a, 2019b). Pre-service teachers in this study were unlikely to utilize technology for teaching merely because people who are important to them thought it should or should not be used; they needed to have a favorable attitude about usefulness as well.

In accordance with the findings of Huang et al. (2020b) and Abdullah and Ward (2016), subjective norm was also found to significantly predict PEU. In addition, the 
fact that $\mathrm{H} 2$ and $\mathrm{H} 6$ were supported in this study and H5 was not, show that PEU had mediated the effect of SN on BI. When pre-service teachers think that people who are important to them will support their use of technology in the classroom, they perceive technology as easy to use, which leads to a positive behavioral intention to use it.

This study reported significant negative impact of TC on PEU suggesting that the more time and difficulty it takes for pre-service teachers to grasp and use technology in the classroom, the less they will perceive it as effortless i.e. easy to use. This is supported by a research involving university teachers in China (Teo et al., 2018). On the other hand, our findings contradict those of Huang et al. (2020a), who investigated possible antecedents of perceived ease of Internet use for learning among Chinese higher-education students. Because university students are digital natives who grew up with the Internet and technology, it is expected that they may have a better degree of technological proficiency than university teachers. It is likely that they do not see using the Internet for learning as a complicated activity. On the other hand, teachers and pre-service teachers may struggle with how to utilize technology to improve teaching and see it as a complex activity that affect their PEU, which may explain the significance of the TC-PEU connection. Also, in another study, Huang et al. (2021) found that university teachers in China demonstrated characteristics similar to digital natives.

When it comes to integrating technology into the classroom, it appears to be more difficult than using the Internet for learning. The research' conflicting findings can be more attributed to the diverse use of technology than generations polled in mentioned studies. This discrepancy emphasizes the need of taking context of technology use into account when it comes to technological acceptance and behavior, not only user characteristics.

All of the hypotheses involving digital nativeness were supported (H8 to H12) demonstrating the power of DN in predicting pre-service teachers' acceptance of technology in the future classroom. DN was shown to be a significant positive predictor of PU, implying that the more pre-service teachers perceive they have digital native traits, the more they perceive technology as being useful in the classroom. This finding is consistent with some other research on information systems acceptance (Kesharwani, 2020; Metallo \& Agrifoglio, 2015). According to Kesharwani (2020), DNs are better than digital immigrants at evaluating usefulness of information systems. Metallo and Agrifoglio (2015) examined the impact of generational differences on Twitter usage and found that digital natives perceive Twitter to be less useful than do digital immigrants. Most age-related research in the field of information systems implies that older users find technology less useful than younger users (Chung et al., 2010; Morris \& Venkatesh, 2000; Morris et al., 2005). Prensky (2007) claims that students are demanding that these [new] technology be integrated into their education "in part because they are things that the students have already mastered and use in their daily lives, and in part because they realise just how useful they can be" (p. 41).

The fact that DN has a direct significant impact on the SN in this study indicated that the more digital native traits pre-service teachers believe they possess, the more they perceive social pressure to use technology. According to studies, younger 
generations, who probably have more DN characteristics, are more sensitive to social pressure from superiors and peers than elder generations (Vodanovich et al., 2010). Metallo and Agrifoglio (2015) found that digital natives experience more social pressure to use Twitter than do digital immigrants. On the other hand, Morris and Venkatesh (2000) discovered that in the initial decision to adopt new technology, older workers are more motivated by social factors than younger employees. Kesharwani (2020) found that instructors' influence would better explain digital natives' adoption of an IS than that of digital immigrants under sequential belief updating. Although the impact of social pressure varies depending on the technology and context, it is clear that users with distinct digital native characteristics perceive it differently.

This study revealed that DN has a significant negative impact on TC, confirming that the more pre-service teachers believe they possess digital native traits, the less time and difficulty it takes them to grasp and use technology. This is in line with Prensky (2001) who suggested that digital immigrants as "non-native speakers" of the digital language have additional challenges in adjusting to the new, rapidly changing technical world.

We discovered that DN has a significant effect on PEU, indicating that pre-service teachers who believe they possess digital native characteristics are more likely to perceive technology as easy to use i.e. effortless. This is in line with findings of Metallo and Agrifoglio (2015) who found significant impact of DN-DI on PEU $(p \leq 0.001)$. Kesharwani (2020) stated that digital natives spend more time with omnipresent technology than digital immigrants, implying that DNs are more computer-involved than DIs, and find technology more useful, and easier to use. Younger generations are more prone than elder generations to see technology as effortless since they are more accustomed with and oriented to it (Chung et al., 2010).

Our findings demonstrated that DN had the strongest explanatory power on BI. This was in line with Zhao and Zhao (2021). Pre-service teachers who believe they possess digital native characteristics are more likely to use technology in their future teaching. Under sequential belief updating, Kesharwani (2020) found that behavioral intention would better explain digital natives' adoption of an IS than that of digital immigrants.

It is reasonable to believe that if pre-service teachers consider they have digital native traits, they will think utilizing technology in the classroom is useful and easy, feel social pressure to use it, think technology is less complicated, and will be more inclined to use it.

Although the results in this study supported all TAM hypotheses as expected, it revealed new information about digital nativeness and its link to other TAM variables, as well as subjective norms and technological complexity. When evaluating the factors that influence pre-service teachers' acceptance of technology in the future classroom, we found that digital nativeness is a significant variable. The findings explain pre-service teachers' intrinsic and extrinsic motivation to employ technology in their future teaching in Serbia. 


\subsection{Limitation of the study and future research}

This research has a number of limitations. First, data was obtained using selfreports. While helpful and practical for technology acceptance studies, researchers have cautioned about using self-reports since the data may lead to response biases and may not reflect participants' real feelings (Fan et al., 2006).

Second, other factors, such as information literacy (Çoklar et al., 2017), TPCK and experience (Teo et al., 2017; Milutinović, 2016) or satisfaction, perceived voluntariness, and habit (Chen et al., 2015), might be included in the model to better explain pre-service teachers' intention to use technology in the future classroom.

Third, because our sample was limited to just pre-service teachers from a single developing country, the sample selection procedure may have been biased, limiting the generalizability of the findings in this study. This sample's profile may not be representative of pre-service teachers in general due to cultural and socio-political factors. Additionally, in this research, there were far more female in the sample than male, and the effect of gender is usually related with culture, which may also introduce a bias in the results.

To further explain disparities, future study may compare in-service teachers to pre-service teachers from developed and developing countries. An additional qualitative study, done as a supplement, could enhance interpretation of the results and depth of understanding pre-service teachers' technology usage.

Furthermore, it would be useful to examine the relationships among experience with technology, digital competency, information literacy and digital native traits in the future research.

\subsection{Implications of the study}

The findings contribute significantly to both theory and practice. This study addressed the research question of whether DNAS (Teo, 2013) could be useful in measuring the digital native traits by verifying the factorial structure of the DNAS using a sample of pre-service teachers in Serbia. Furthermore, the study validated a model that may be used to predict pre-service teachers' use of technology in future teaching, which is the study's theoretical contribution. This research has the potential to add to current arguments over the usefulness of DNAS and an extended TAM as a suggested model for explaining and predicting pre-service teachers' technology usage, as well as existing literature on pre-service teachers' technology acceptance. Furthermore, using an extended TAM in a developing country enables for the validation and robustness of the findings in both similar and different contexts.

The findings can help policymakers and teacher educators to get a better understanding of the factors that impact pre-service teachers' acceptance of technology in developing countries like Serbia. The inclusion of DN to the TAM, which is already extended with SN and TC, adds to our comprehension of the issue. The findings of this study showed that an extended model with six variables (DN, SN, TC, PEU, $\mathrm{PU}$, and BI) could be evaluated and examined among users in cultures where technological development is limited to determine the amount of variance explained in 
technology acceptance among pre-service teachers. Other significant factors from the practice and theory, such as information literacy, experience, TPCK, satisfaction, perceived voluntariness and habit, should also be considered.

In terms of practice, this research has the potential to enlighten teacher educators in other developing countries with educational systems that are comparable to Serbia's, including countries in the Balkan area, Central Asia, and Latin America.

For example, all parties involved in pre-service teacher education (i.e. legislators, managers, and teacher educators) should encourage pre-service teachers to use technology and provide opportunities for them to do so successfully. Aside from digital skills, pre-service teachers should have their attitudes and perceptions addressed during their education. Furthermore, it should incorporate teaching activities to assist pre-service teachers in cultivating positive attitudes toward technology's usefulness and ease of use in order to improve their inclination to use it. If this were the case, pre-service teachers would be more motivated to use technology in their pedagogical practice in the future.

Digital technology immersion is not age-dependent, since elder populations could grow accustomed to it, while younger generations can focus on a smaller number of new technologies and their characteristics (Margaryan et al., 2011).

Several scholars have argued that today's students are not "natively" competent (Bennett \& Maton, 2010; Marksbury \& Bryant, 2019). It should be clear that the terms "digital native" and "technological literacy" or "digital literacy" are not synonymous. In the study on the effects of pre-service teachers' digital native traits and information literacy on online information search competency, Çoklar et al. (2017) found that both factors are significant predictors of competency with stronger correlations with information literacy than with digital native traits. Promoting information literacy, coupled with improving technical skills, is essential for digital natives to fully exploit the Internet's abundant potential (Çoklar et al., 2017). According to the findings of Aharony and Gazit (2019), students who grew up with technology are more likely to have greater information literacy selfefficacy. Shonfeld et al. (2021) found positive relationships between information literacy self-efficacy and digital native traits, as well as computer abilities.

Yurdakul (2018) found that technological pedagogical content knowledge (TPCK) competence is significantly influenced by digital native traits. TPCK consists of technological, pedagogical, and content knowledge (Mishra \& Koehler, 2006). It reflects a large body of advanced expertise on how to use technologies to enhance teaching. The results of a Serbian study examining the factors that may influence pre-service teachers' adoption of innovative computer use in teaching mathematics showed that technological pedagogical content knowledge (TPCK) had the strongest explanatory power on BI, followed by experience and attitude (Teo et al., 2017;Milutinović, 2016). Pre-service teachers' TPCK needs to be upgraded through experience during education in order to result in positive attitudes towards applying technology and their acceptance of technology as useful and easy to implement in teaching and learning. Consequently, the influence of this practice may increase the pre-service teachers' intentions to utilise technology in their teaching. 
Digital nativeness may not imply pre-service teachers' digital literacy, in its various forms; digital fluency, and digital citizenship, but our findings demonstrate that it does influence their intention to use technology. Digital nativeness may also influence their TPCK, information literacy self-efficacy, information search competency. The findings of Della Ventura (2020) demonstrate that when students take control of the learning process via the use of technology, they may enhance their digital abilities. Teachers should learn to recognize their students' digital native traits encouraging them to take charge of the learning process, teaching them the digital literacy pillars and allowing them to apply those pillars to meaningful purposes.

\section{Conclusion}

This study investigated digital nativeness of pre-service teachers and its connection to the other variables that might predict intention to utilize technology in the future classroom in Serbia. The Technology Acceptance Model (TAM) was expanded to include digital nativeness, subjective norm, and technological complexity to explain the participants' intention to use technology.

Given the scarcity of similar studies in the Balkans, this study is one of the few that fills in gaps left by previous research on pre-service teachers' digital nativeness and technology adoption. It serves as a timely reminder to academics and practitioners to maximize the benefits of students' familiarity with technology in order to help teachers and students achieve their learning outcomes.

\section{Appendix. List of constructs and corresponding items used in this study}

\section{Digital nativeness (adapted from Teo, 2013)}

I use the internet every day.

I use technologies for many things in my daily life.

When I need to know something, I search the internet first.

I use technologies for leisure every day.

I keep in contact with my friends through technologies every day.

I am able to surf the internet and perform another activity comfortably.

I can check email and chat online at the same time.

When using the internet for my work, I am able to listen to music as well.

I am able to communicate with my friends and do my work at the same time.

I am able to use more than one application on the computer at the same time.

I can chat on the phone with a friend and message another at the same time.

I use pictures more than words when I wish to explain something.

I use a lot of graphics and icons when I send messages.

I prefer to receive messages with graphics and icons.

I use pictures to express my feelings better.

I use smiley faces a lot in my messages. 
I wish to be rewarded for everything I do.

I expect quick access to information when I need it.

When I send out an email, I expect a quick reply.

I expect the websites that I visit regularly to be constantly updated.

When I study, I prefer to learn those that I can use quickly first.

Technological Complexity adapted from Thompson et al. (1991), Teo (2009b)

Using technologies is so complicated that it is difficult to know what is going on.

Using technologies involves too much time.

It takes too long to learn how to use the technologies.

Subjective Norm adapted from Taylor and Todd (1995), Venkatesh et al. (2003), Teo (2009b)

People whose opinions I value will encourage me to use technologies.

People who are important to me will support me to use technologies.

People who influence my behaviour think that I should use the technologies.

Perceived Usefulness (adapted from Davis, 1989) Teo (2009b)

Using technologies will improve my work.

Using technologies will enhance my effectiveness.

Using technologies will increase my productivity.

I find technologies a useful tool in my work.

Perceived Ease of Use adapted from Teo (2009b)

My interaction with technologies is clear and understandable.

I find it easy to get technologies to do what I want it to do.

I find technologies easy to use.

It would be easy for me to become skillful at using the technologies.

Behavioural Intention to Use technologies in the Future Vocation (adapted from Davis, 1989)

I plan to use technologies often for teaching.

I will probably use technologies for teaching as soon as I start working.

I will use technologies for teaching in future.

Authors' contribution The study conception and design, material preparation, data collection and analysis, writing, review and editing of the manuscript were performed by Verica Milutinović.

\section{Declarations}

Financial interests The author declares that she has no financial interests.

Non-financial interests none.

Competing interests The author have no competing interests to declare that are relevant to the content of this article. 


\section{References}

Abdullah, F., \& Ward, R. (2016). Developing a general extended technology acceptance model for E-Learning (GETAMEL) by analysing commonly used external factors. Computers in Human Behavior, 56, 238-256. https://doi.org/10.1016/j.chb.2015.11.036

Aharony, N., \& Gazit, T. (2019). Factors affecting students' information literacy self-efficacy. Library Hi Tech, 37(2), 183-196. https://doi.org/10.1108/LHT-10-2018-0154

Ajzen, I. (1991). The theory of planned behavior. Organizational Behavior and Human Decision Processes, 50, 179-211. https://doi.org/10.1016/0749-5978(91)90020-T

Akçayır, M., Dündar, H., \& Akçayır, G. (2016). What makes you a digital native? Is it enough to be born after 1980? Computers in Human Behavior, 60, 435-440. https://doi.org/10.1016/j.chb.2016.02.089

Anderson, J. C., \& Gerbing, D. W. (1988). Structural equation modeling in practice: A review and recommended two-step approach. Psychological Bulletin, 103(3), 411-423.

Bennett, S., \& Maton, K. (2010). Beyond the 'digital natives' debate: Towards a more nuanced understanding of students' technology experiences. Journal of Computer Assisted Learning, 26(5), 321331. https://doi.org/10.1111/j.1365-2729.2010.00360.x

Bennett, S., Maton, K., \& Kervin, L. (2008). The 'digital natives' debate: A critical review of the evidence. British Journal of Educational Technology, 39(5), 775-786. https://doi.org/10.1111/j.14678535.2007.00793.x

Boomsma, A. (1987). The robustness of maximum likelihood estimation in structural equation models. In P. Cuttance \& R. Ecob (Eds.), Structural modeling by example: Applications in educational, sociological, and behavioral research (pp. 160-188). Cambridge University Press.

Chen, C. P., Lai, H. M., \& Ho, C. Y. (2015). Why do teachers continue to use teaching blogs? The roles of perceived voluntariness and habit. Computers \& Education, 82, 236-249. https://doi.org/10. 1016/j.compedu.2014.11.017

Chen, P. H., Teo, T., \& Zhou, M. (2016). Relationships between digital nativity, value orientation, and motivational interference among college students. Learning and Individual Differences, 50, 49-55. https://doi.org/10.1016/j.lindif.2016.06.017

Cheung, C. M., Lee, M. K., \& Chen, Z. (2002). Using the internet as a learning medium: An exploration of gender difference in the adoption of FaBWeb. In Proceedings of the 35th Annual Hawaii International Conference on System Sciences (pp. 475-483). IEEE.

Chung, J. E., Park, N., Wang, H., Fulk, J., \& McLaughlin, M. (2010). Age differences in perceptions of online community participation among non-users: An extension of the technology acceptance model. Computers in Human Behavior, 26(6), 1674-1684. https://doi.org/10.1016/j.chb.2010.06. 016

Çoklar, A. N., Yaman, N. D., \& Yurdakul, I. K. (2017). Information literacy and digital nativity as determinants of online information search strategies. Computers in Human Behavior, 70, 1-9. https://doi. org/10.1016/j.chb.2016.12.050

Davis, F. D. (1989). Perceived usefulness, perceived ease of use, and user acceptance of information technology. MIS Quarterly, 13(3), 319-340. https://doi.org/10.2307/249008

Davis, F. D., Bagozzi, R. P., \& Warshaw, P. R. (1989). User acceptance of computer technology: A comparison of two theoretical models. Management Science, 35(8), 982-1003. https://doi.org/10.1287/ mnsc.35.8.982

Della Ventura M. (2020) Removing Digital Natives from Technological Illiteracy with the Weblog. In: Huang TC., Wu TT., Barroso J., Sandnes F.E., Martins P., Huang YM. (eds) Innovative Technologies and Learning. ICITL 2020. Lecture notes in computer science, vol 12555, (pp. 598-609), Springer, Cham. https://doi.org/10.1007/978-3-030-63885-6_65

Fan, X., Miller, B. C., Park, K. E., Winward, B. W., Christensen, M., Grotevant, H. D., \& Tai, R. H. (2006). An exploratory study about inaccuracy and invalidity in adolescent self-report surveys. Field Methods, 18(3), 223-244. https://doi.org/10.1177/152822X06289161

Fathali, S., \& Okada, T. (2018). Technology acceptance model in technology-enhanced OCLL contexts: A self-determination theory approach. Australasian Journal of Educational Technology, 34(4), 138154. https://doi.org/10.14742/ajet.3629.

Fishbein, M., \& Ajzen, I. (1975). Belief, attitude, intention and behavior: An introduction to theory and research. Addison-Wesley. 
Fornell, C., \& Larcker, D. F. (1981). Evaluating structural equation models with unobservable variables and measurement error. Journal of Marketing Research, 48, 39-50. https://doi.org/10.1177/00222 4378101800104.

Fraillon, J., Ainley, J., Schulz, W., Friedman, T., \& Gebhardt, E. (2014). Preparing for life in a digital age - the IEA international computer and information literacy study international report. Springer International Publishing. https://doi.org/10.1007/978-3-319-14222-7

Hair Jr., J. F., Black, W. C., Babin, B. J., \& Anderson, R. E. (2010). Multivariate data analysis (seventh ed.). Prentice-Hall International.

Helsper, E. J. (2020). Digital inequalities amongst digital natives. In The Routledge companion to digital media and children (pp. 435-448). Routledge.

Helsper, E. J., \& Eynon, R. (2010). Digital natives: Where is the evidence? British Educational Research Journal, 36(3), 503-520. https://doi.org/10.1080/01411920902989227

Hofstede, G., Hofstede, G. J., \& Minkov, M. (2005). Cultures and organizations: Software of the mind (Vol. 2). Mcgraw-hill.

Hoyle, R. H. (2011). Structural equation modeling for social and personality psychology. Sage.

Hsieh, J. P. A., Rai, A., \& Keil, M. (2011). Addressing digital inequality for the socioeconomically disadvantaged through government initiatives: Forms of capital that affect ICT utilization. Information Systems Research, 22(2), 233-253.

Huang, F., Teo, T., \& Scherer, R. (2020a). Investigating the antecedents of university students' perceived ease of using the internet for learning. Interactive learning environments, 1-17. https://doi.org/10. $1080 / 10494820.2019 .1710540$

Huang, F., Teo, T., \& Zhou, M. (2020b). Chinese students' intentions to use the internet-based technology for learning. Educational Technology Research and Development, 68(1), 575-591. https://doi. org/10.1007/s11423-019-09695-y

Huang, F., Teo, T., \& He, J. (2021). Digital nativity of university teachers in China: Factor structure and measurement invariance of the Digital Native Assessment Scale (DNAS). Interactive Learning Environments, 29(3), 385-399. https://doi.org/10.1080/10494820.2019.1570278

Judd, T. (2018). The rise and fall (?) of the digital natives. Australasian Journal of Educational Technology, 34(5), 99-119. 10.14742/ajet.3821.

Kafyulilo, A., Fisser, P., Pieters, J., \& Voogt, J. (2015). ICT use in science and mathematics teacher education in Tanzania: Developing technological pedagogical content knowledge. Australasian Journal of Educational Technology, 31(4), 381-399. 10.14742/ajet.1240.

Kesharwani, A. (2020). Do (how) digital natives adopt a new technology differently than digital immigrants? A longitudinal study. Information \& Management, 57(2), 103170. https://doi.org/10.1016/j. im.2019.103170

Khlaisang, J., Teo, T., \& Huang, F. (2021). Acceptance of a flipped smart application for learning: A study among Thai university students. Interactive Learning Environments, 29(5), 772-789. https:// doi.org/10.1080/10494820.2019.1612447

Kirschner, P. A., \& De Bruyckere, P. (2017). The myths of the digital native and the multitasker. Teaching and Teacher Education, 67, 135-142. https://doi.org/10.1016/j.tate.2017.06.001

Kline, R. B. (2011). Principles and practice of structural equation modelling (3rd ed.). Guilford Press.

Lai, H. M., \& Chen, C. P. (2011). Factors influencing secondary school teachers' adoption of teaching blogs. Computers \& Education, 56(4), 948-960. https://doi.org/10.1016/j.compedu.2010.11.010

Liu, H., Wang, L., \& Koehler, M. J. (2019). Exploring the intention-behavior gap in the technology acceptance model: A mixed-methods study in the context of foreign language teaching in China. British Journal of Educational Technology, 50(5), 2536-2556. https://doi.org/10.1111/bjet.12824

Ma, W. W. K., Andersson, R., \& Streith, K. O. (2005). Examining user acceptance of computer technology: An empirical study of student teachers. Journal of Computer Assisted Learning, 21(6), 387395. https://doi.org/10.1111/j.1365-2729.2005.00145.x

Mardia, K. V. (1970). Measures of multivariate skewness and kurtosis with applications. Biometrika, 36, 519-530. https://doi.org/10.1093/biomet/57.3.519

Margaryan, A., Littlejohn, A., \& Vojt, G. (2011). Are digital natives a myth or reality? University students' use of digital technologies. Computers \& Education, 56(2), 429-440. https://doi.org/10. 1016/j.compedu.2010.09.004

Marksbury, N., \& Bryant, E. A. (2019). Enter the twilight zone: The paradox of the digital native. Issues in Information Systems, 20(2), 206-215. 10.48009/2_iis_2019_206-215.

Mei, B., Brown, G. T., \& Teo, T. (2018). Toward an understanding of preservice English as a foreign language teachers' acceptance of computer-assisted language learning 2.0 in the 
People's Republic of China. Journal of Educational Computing Research, 56(1), 74-104. $10.1177 \% 2$ F0735633117700144.

Metallo, C., \& Agrifoglio, R. (2015). The effects of generational differences on use continuance of twitter: An investigation of digital natives and digital immigrants. Behaviour \& Information Technology, 34(9), 869-881. https://doi.org/10.1080/0144929X.2015.1046928

Mishra, P., \& Koehler, M. (2006). Technological pedagogical content knowledge: A framework for teacher knowledge. The Teachers College Record, 108(6), 1017-1054 Retrieved October 17, 2021 from https://www.learntechlib.org/p/99246/

Milutinović, V. (2016). An exploration of acceptance of innovative computer use in teaching mathematics among pre-service class teachers and mathematics teachers. Zbornik Instituta za pedagoska istrazivanja, 48(2), 339-366. https://doi.org/10.2298/ZIPI1602339M

Morris, M. G., \& Venkatesh, V. (2000). Age differences in technology adoption decisions: Implications for a changing work force. Personnel Psychology, 53(2), 375-403. https://doi.org/10.1111/j.17446570.2000.tb00206.x

Morris, M. G., Venkatesh, V., \& Ackerman, P. L. (2005). Gender and age differences in employee decisions about new technologies: An extension to the theory of planned behavior. IEEE Transactions on Engineering Management, 52, 69-84. https://doi.org/10.1109/TEM.2004.839967

Motaghian, H., Hassanzadeh, A., \& Moghadam, D. K. (2013). Factors affecting university instructors' adoption of web-based learning systems: Case study of Iran. Computers \& Education, 61, 158-167. https://doi.org/10.1016/j.compedu.2012.09.016

Munoz-Carril, P. C., Gonzalez-Sanmamed, M., \& Fuentes-Abeledo, E. J. (2020). Use of blogs for prospective early childhood teachers. Educación XX1, 23(1), 247-273. https://doi.org/10.5944/educx $\mathrm{x} 1.23768$

OECD. (2015). Students, Computers and Learning: Making the Connection. Paris: OECD Publishing. https://doi.org/10.1787/9789264239555-en.

Prensky, M. (2001). Digital natives, digital immigrants. On the Horizon., 9(5), 1-6. https://doi.org/10. $1108 / 10748120110424816$

Prensky, M. (2007). How to teach with technology: Keeping both teachers and students comfortable in an era of exponential change. Emerging Technologies for Learning, 2(4), 40-46.

Pynoo, B., Tondeur, J., Braak, J. V., Duyck, W., Sijnave, B., \& Duyck, P. (2012). Teachers' acceptance and use of an educational portal. Computers \& Education, 58, 1308-1317. https://doi.org/10.1016/j. compedu.2011.12.026

Raykov, T., \& Marcoulides, G. A. (2008). An introduction to applied multivariate analysis. Taylor \& Francis.

Rogers, E. M., \& Shoemaker, F. F. (1971). Communication of innovations. Free Press, New York, NY.

Schepers, J., \& Wetzels, M. (2007). A meta-analysis of the technology acceptance model: Investigating subjective norm and moderation effects. Information \& Management, 44, 90-103. https://doi.org/ 10.1016/j.im.2006.10.007

Scherer, R., Siddiq, F., \& Tondeur, J. (2019). The technology acceptance model (TAM): A meta-analytic structural equation modeling approach to explaining teachers' adoption of digital technology in education. Computers \& Education, 128, 13-35. https://doi.org/10.1016/j.compedu.2018.09.009

Schumacker, R. E., \& Lomax, R. G. (2010). A beginner's guide to structural equation modeling (3rd ed.). Routledge.

Shonfeld, M., Aharony, N., \& Nadel-Kritz, N. (2021). Teachers' perceived information literacy self-efficacy. Journal of Librarianship and Information Science. https://doi.org/10.1177/09610006211026950

Siddiq, F., Scherer, R., \& Tondeur, J. (2016). Teachers' emphasis on developing students' digital information and communication skills (TEDDICS): A new construct in 21 st century education. Computers \& Education, 92-93, 1-14. https://doi.org/10.1016/j.compedu.2015.10.006

Steiger, J. H. (2007). Understanding the limitations of global fit assessment in structural equation doi: Modeling. Personality and Individual Differences, 42, 893-898. https://doi.org/10.1016/j.paid.2006. 09.017

Straub, E. T. (2009). Understanding technology adoption: Theory and future directions for informal learning. Review of Educational Research, 79(2), 625-649. https://doi.org/10.3102/0034654308325896

Taylor, S., \& Todd, P. (1995). Understanding information technology usage: A test of competing models. Information Systems Research, 6(2), 144-176. https://doi.org/10.1287/isre.6.2.144

Teo, T. (2009a). Is there an attitude problem? Reconsidering the role of attitude in the TAM. British Journal of Educational Technology, 40(6), 1139-1141. https://doi.org/10.1111/j.1467-8535.2008. 00913.x 
Teo, T. (2009b). Modelling technology acceptance in education: A study of pre-service teachers. Computers \& Education, 52, 302-312. https://doi.org/10.1016/j.compedu.2008.08.006

Teo, T. (2013). An initial development and validation of a digital natives assessment scale (DNAS). Computers \& Education, 67, 51-57. https://doi.org/10.1016/j.compedu.2013.02.012

Teo, T. (2016). Do digital natives differ by computer self-efficacy and experience? An empirical study. Interactive Learning Environments, 24(7), 1725-1739. https://doi.org/10.1080/10494820.2015. 1041408

Teo, T., \& Milutinović, V. (2015). Modelling the intention to use technology for teaching mathematics among pre-service teachers in Serbia. Australasian Journal of Educational Technology, 31(4), 363-380. 10.14742/ajet.1668.

Teo, T., \& van Schaik, P. (2012). Understanding the intention to use technology by pre-service teachers: An empirical test of competing theoretical models. International Journal of Human-Computer Interaction, 28(3), 178-188. https://doi.org/10.1080/10447318.2011.581892

Teo, T., \& Van Schalk, P. (2009). Understanding technology acceptance in pre-service teachers: A structural-equation modeling approach. Asia-Pacific Education Researcher, 18(1), 47-66. https://doi.org/ 10.3860/taper.v18i1.1035

Teo, T., Khlaisang, J., Thammetar, T., Ruangrit, N., Satiman, A., \& Sunphakitjumnong, K. (2014). A survey of pre-service teachers' acceptance of technology in Thailand. Asia Pacific Education Review, 15(4), 609-616. https://doi.org/10.1007/s12564-014-9348-3

Teo, T., Kabakçı Yurdakul, I., \& Ursavaş, Ö. F. (2016). Exploring the digital natives among pre-service teachers in Turkey: A cross-cultural validation of the digital native assessment scale. Interactive Learning Environments, 24(6), 1231-1244. https://doi.org/10.1080/10494820.2014.980275

Teo, T., Milutinović, V., Zhou, M., \& Banković, D. (2017). Traditional vs. innovative uses of computers among mathematics pre-service teachers in Serbia. Interactive Learning Environments, 25(7), 811-827. https://doi.org/10.1080/10494820.2016.1189943

Teo, T., Huang, F., \& Hoi, C. (2018). Explicating the influences that explain intention to use technology among English teachers in China. Interactive Learning Environments, 26(4), 460-475. https://doi. org/10.1080/10494820.2017.1341940

Teo, T., Sang, G., Mei, B., \& Hoi, C. K. W. (2019a). Investigating pre-service teachers' acceptance of Web 2.0 technologies in their future teaching: A Chinese perspective. Interactive Learning Environments, 27(4), 530-546. https://doi.org/10.1080/10494820.2018.1489290

Teo, T., Zhou, M., Fan, A. C. W., \& Huang, F. (2019b). Factors that influence university students' intention to use Moodle: A study in Macau. Educational Technology Research and Development, 67(3), 749-766. https://doi.org/10.1007/s11423-019-09650-x

Thinyane, H. (2010). Are digital natives a world-wide phenomenon? An investigation into South African first year students' use and experience with technology. Computers \& Education, 55(1), 406-414. https://doi.org/10.1016/j.compedu.2010.02.005

Thompson, R. L., Higgins, C. A., \& Howell, J. M. (1991). Personal computing: Toward a conceptual model of utilization. MIS Quarterly, 15(1), 124-143. https://doi.org/10.2307/249443

Tsai, Y. R. (2015). Applying the technology acceptance model (TAM) to explore the effects of a course management system (CMS)-assisted EFL writing instruction. CALICO Journal, 32(1), 153-171 Retrieved October 17, 2021 from https://www.jstor.org/stable/calicojournal.32.1.153

UNESCO-IBE. (2011). Republic of Serbia, world data on education (7th ed.) 2010/11. http://www.ibe.unesco. org/fileadmin/user_upload/Publications/WDE/2010/pdf-versions/Serbia.pdf. Accessed 17 Oct 2021.

Venkatesh, V., Morris, M., Davis, G., \& Davis, F. (2003). User acceptance of information technology: Toward a unified view. MIS Quarterly, 27(3), 425-478. https://doi.org/10.2307/30036540

Vodanovich, S., Sundaram, D., \& Myers, M. (2010). Research commentary-Digital natives and ubiquitous information systems. Information Systems Research, 21(4), 711-723. https://doi.org/10.1287/ isre. 1100.0324

Wagner, V., \& Acier, D. (2017). Factor structure evaluation of the French version of the digital natives assessment scale. Cyberpsychology, Behavior and Social Networking, 20(3), 195-201. https://doi. org/10.1089/cyber.2016.0438

Wang, H. Y., Sigerson, L., \& Cheng, C. (2019). Digital nativity and information technology addiction: Age cohort versus individual difference approaches. Computers in Human Behavior, 90, 1-9. https://doi.org/10.1016/j.chb.2018.08.031

Wilson, M. L., Hall, J. A., \& Mulder, D. J. (2020). Assessing digital nativeness in pre-service teachers: Analysis of the digital natives assessment scale and implications for practice. Journal of Research on Technology in Education, 1-18. https://doi.org/10.1080/15391523.2020.1846146 
Yong, S. T., \& Gates, P. (2014). Born digital: Are they really digital natives?. International Journal of e-Education, e-Business, e-Management and e-Learning, 4(2), 102.

Yurdakul, I. K. (2018). Modeling the relationship between pre-service teachers' TPACK and digital nativity. Educational Technology Research and Development, 66(2), 267-281. https://doi.org/10. 1007/s11423-017-9546-x

Zhao, C., \& Zhao, L. (2021). Digital nativity, computer self-efficacy and technology adoption: A study among university faculties in China. Frontiers in Psychology, 4112. https://doi.org/10.3389/fpsyg. 2021.746292

Publisher's note Springer Nature remains neutral with regard to jurisdictional claims in published maps and institutional affiliations. 